\title{
Renal artery aneurysm with an ovarian vein thrombosis
}

\author{
Arun Chawla, Dilip Mishra, Pritam Sharma
}

Department of Urology, Kasturba Medical College, Manipal, Karnataka, India

Correspondence to Dr Arun Chawla, urologyarun@yahoo.com

\section{DESCRIPTION}

A 49-year-old female patient presented with a history of post menopausal bleeding and dull aching epigastric pain of 1 month duration. Physical examination revealed anaemia and a few dilated abdominal wall veins. Gynecological examination was normal. Ultrasonography with Doppler evaluation revealed a shrunken left kidney with a large $(5 \times 3 \mathrm{~cm})$ left renal artery aneurysm; right kidney was normal. A contrast-enhanced tomography revealed a $5.3 \times 2.4 \times 3 \mathrm{~cm}$ partially thrombosed left renal artery aneurysm arising $4.5 \mathrm{~mm}$ from the origin of the left renal artery (figure 1), early filling of left renal vein and thrombosis of the left gonadal vein in its entirety (figure 2), large dilated and thrombosed pelvic veins (figure 3), nonfunctioning shrunken left kidney (figure 4).

Renal artery aneurysms (RAA) constitute $1 \%$ of all the aneurysms. ${ }^{1}$ On the basis of autopsy studies, the overall incidence of RAA is $0.1-0.3 \% .^{2}$ There is no absolute predilection for side, but the right side appears to be more common, bilateral aneurysms are observed in $15 \%$. Almost $50 \%$ of RAA are asymptomatic. However, some produce symptoms at a later age due to an increasing size.

Pain (15\%), haematuria (30\%) and hypertension (55\%) secondary to compression of the adjacent parenchyma or to altered blood flow within the vascular tree can occur. Many asymptomatic RAA come to light during a workup of hypertension. Spontaneous gonadal vein thrombosis especially in puerperal women have been reported, they can be asymptomatic or cause potentially catastrophic phenomena such as pulmonary embolism, sepsis or even death. ${ }^{3}{ }^{4}$ Rare causes of this entity are pelvic inflammatory disease, pelvic malignancies, Crohn's disease and pelvic surgical procedures. ${ }^{5} 6$ A thickwalled, enlarged ovarian vein with rim enhancement and central hypodensity are considered the main CT imaging findings of ovarian vein thrombosis. ${ }^{7}$ We presented the first known case of leftsided RAA with associated thrombosis of the left ovarian vein. The cause of this association is unclear.
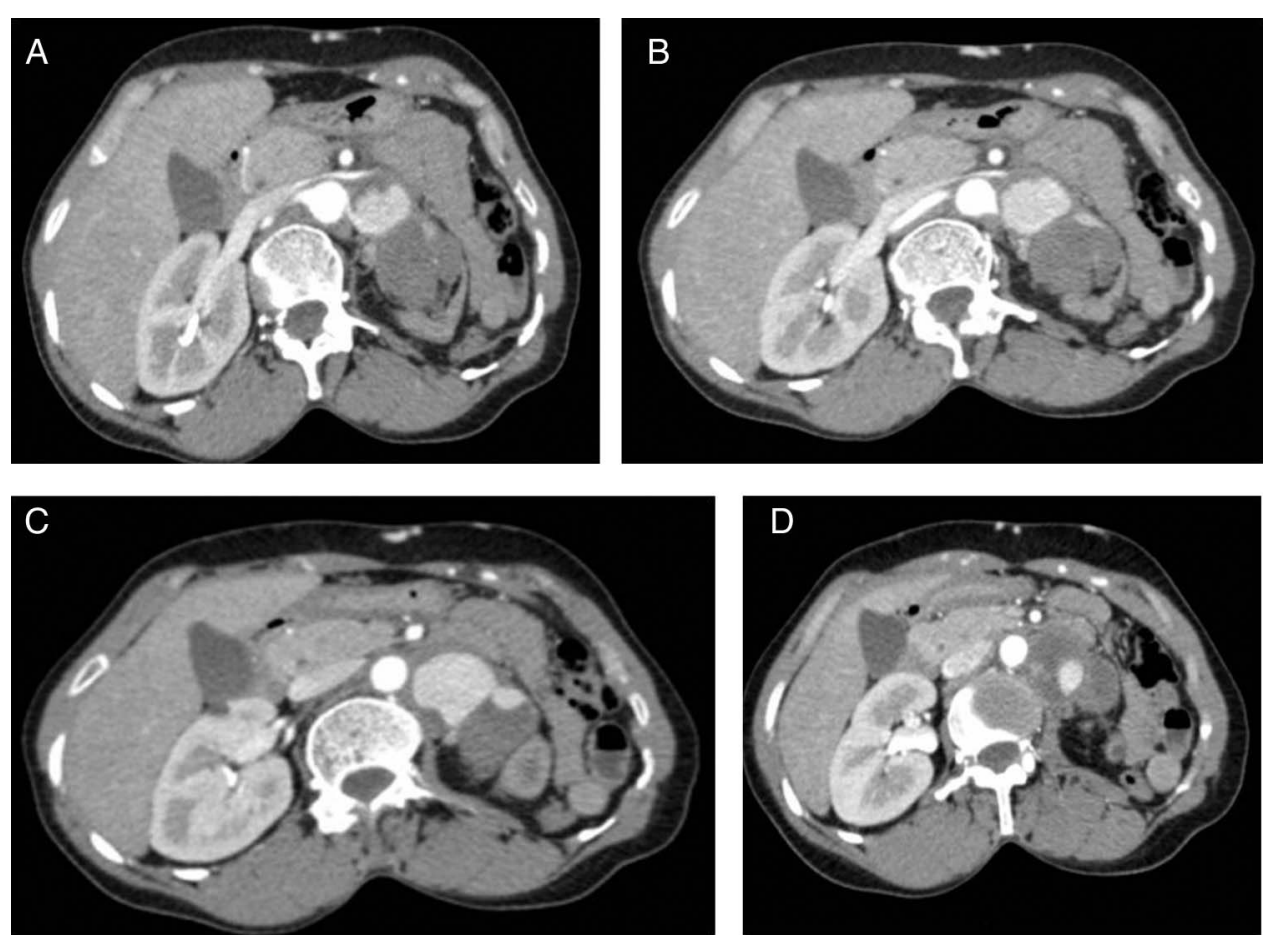

Figure 1 (A-D) Axial images (arterial phase) showing left renal artery aneurysm. Early filling of the left renal vein is seen.
To cite: Chawla $A$

Mishra D, Sharma P. BMJ Case Rep Published online: [please include Day Month Year] doi:10.1136/bcr-2013201490 

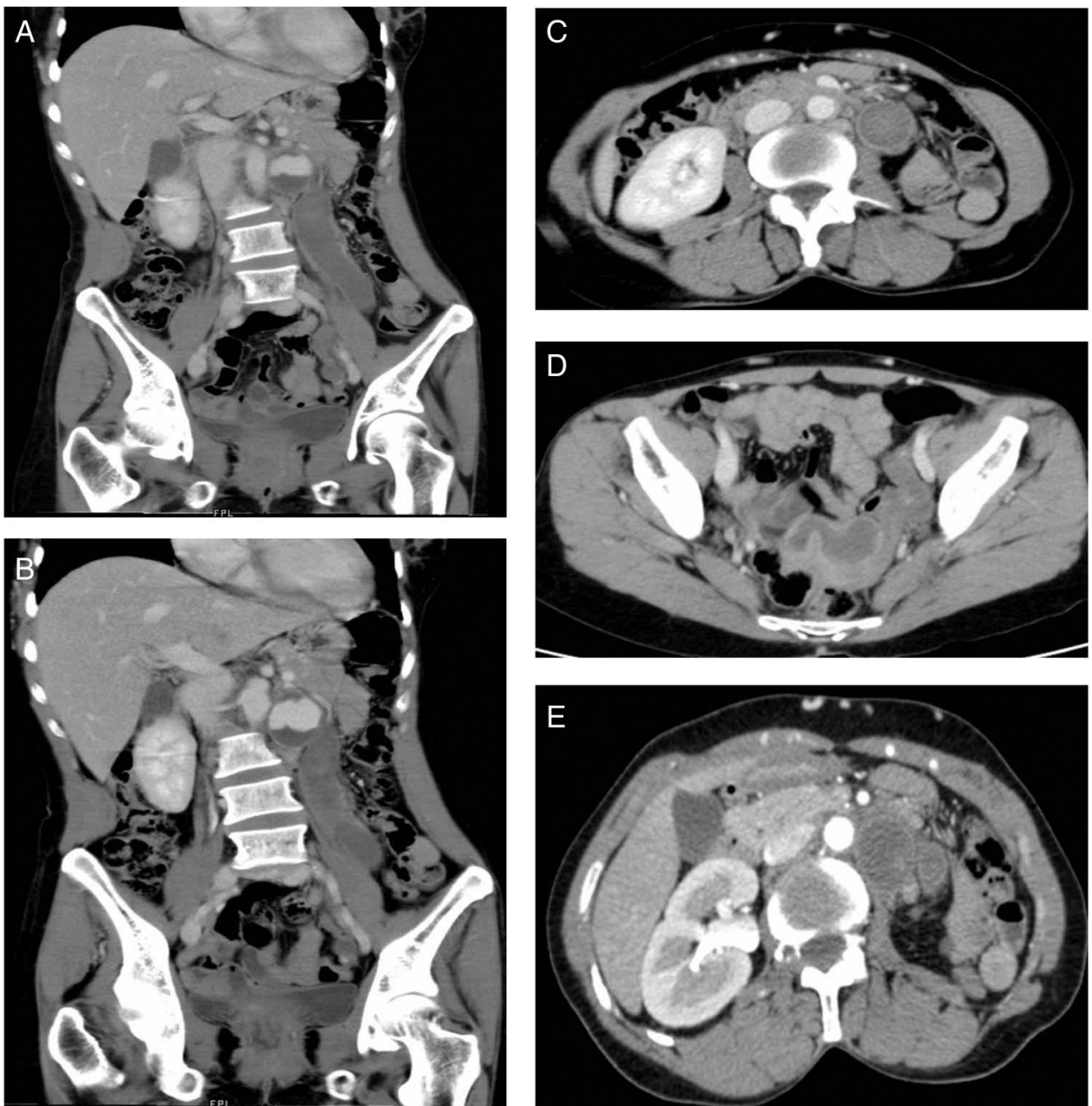

Figure 2 (A and B) Coronal section showing left renal artery aneurysm and thrombosed left gonadal vein. Axial images showing thrombosed gonadal vein in abdomen (C and $\mathrm{D})$ and pelvis $(\mathrm{E})$.
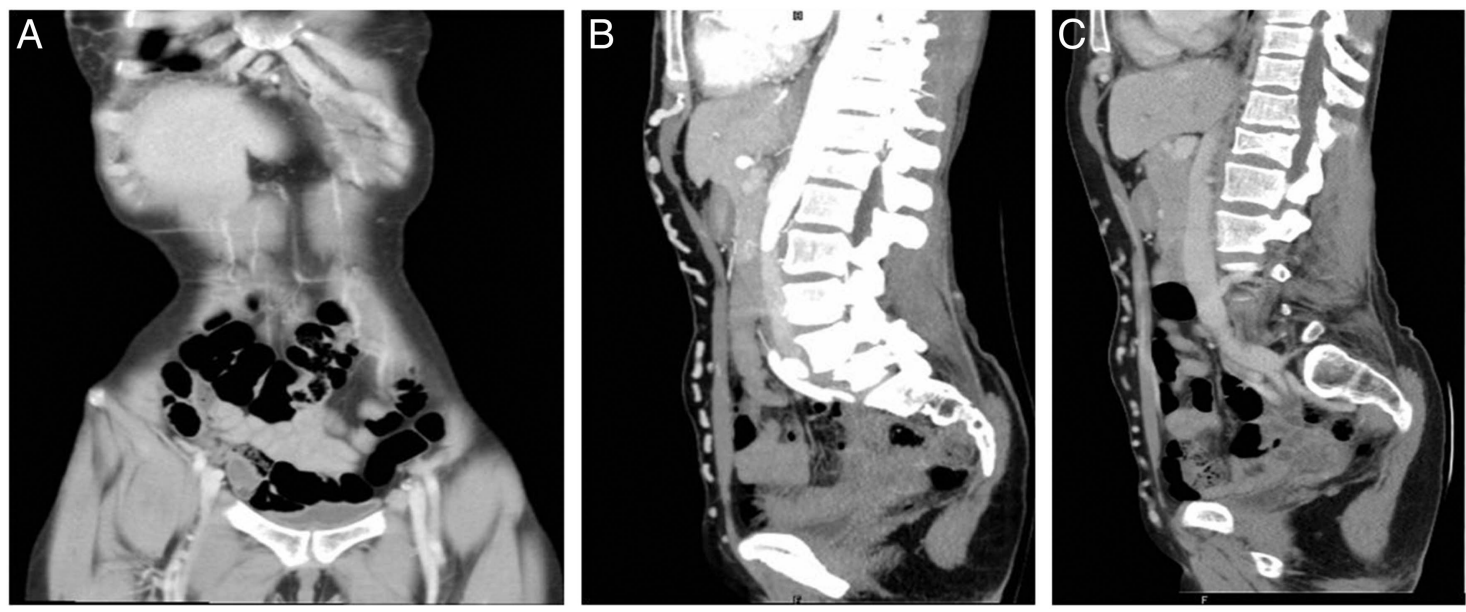

Figure 3 Coronal (A) and saggital view (B and C) showing abdominal wall collaterals. 


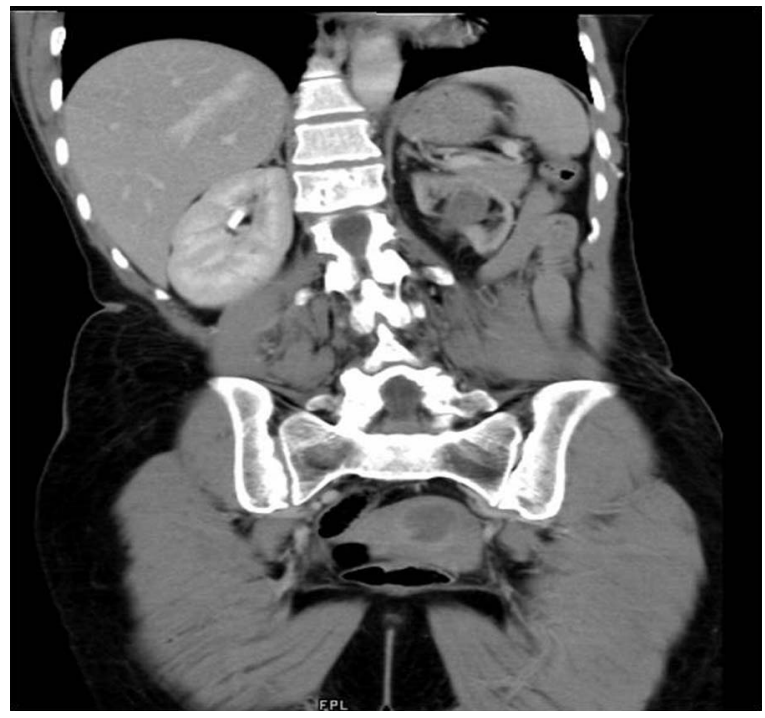

Competing interests None.

Patient consent Obtained.

Provenance and peer review Not commissioned; externally peer reviewed.

\section{REFERENCES}

1 Seppala FE, Levey J. Renal artery aneurysm: case report of a ruptured calcified renal artery aneurysm. Am Surg 1982;48:42-4.

2 Tham G, Ekelund L, Herrlin K, et al. Renal artery aneurysms. Natural history and prognosis. Ann Surg 1983;197:348-52.

3 Hippach M, Meyberg R, Villena-Heinsen C, et al. Postpartum ovarian vein thrombosis. Clin Exp Obstet Gynecol 2000;27:24-6.

4 Henke PK, Cardneau JD, Welling TH III, et al Renal artery aneurysms: a 35-year clinical experience with 252 aneurysms in 168 patients. Ann Surg 2001;234:454-62.

5 Marcovici I, Goldberg H. Ovarian vein thrombosis associated with Crohn's disease: a case report. Am J Obstet Gynecol 2000;182:743-4.

6 Jacoby WT, Cohan RH, Baker ME, et al. Ovarian vein thrombosis in oncology patients: CT detection and clinical significance. Am J Roentgenol 1990;155:291-4.

7 Quane LK, Kidney DD, Cohen AJ. Unusual causes of ovarian vein thrombosis as revealed by CT and sonography. Am J Roentgenol 1998;171:487-90.

Figure 4 Coronal section of contrast-enhanced CT abdomen showing a shrunken non-functioning left kidney.

\section{Learning points}

Aneurysm of the renal artery needs further characterisation with contrast CT with reconstruction.

- Thrombosis of an aneurysm can happen.

- Gonadal (ovarian vein) thrombosis can happen in patients not in the postpartum period.

Copyright 2013 BMJ Publishing Group. All rights reserved. For permission to reuse any of this content visit http://group.bmj.com/group/rights-licensing/permissions.

BMJ Case Report Fellows may re-use this article for personal use and teaching without any further permission.

Become a Fellow of BMJ Case Reports today and you can:

- Submit as many cases as you like

- Enjoy fast sympathetic peer review and rapid publication of accepted articles

- Access all the published articles

- Re-use any of the published material for personal use and teaching without further permission

For information on Institutional Fellowships contact consortiasales@bmjgroup.com

Visit casereports.bmj.com for more articles like this and to become a Fellow 